\title{
INFLUENCE OF PLASMA ELECTROLYTIC HARDENING ON THE STRUCTURE AND PROPERTIES OF 20Cr2Ni4A STEEL
}

\author{
1'Bauyrzhan RAKHADILOV, 'Zarina SATBAYEVA, ${ }^{1}$ Zhuldyz SAGDOLDINA, ${ }^{1}$ Rauan KOZHANOVA \\ ${ }^{1}$ Sarsen Amanzholov East Kazakhstan State University, Ust-Kamenogorsk, Republic of Kazakhstan, \\ satbaeva.z@mail.ru
}

https://doi.org/10.37904/metal.2020.3508

\begin{abstract}
This work presents the results of plasma electrolytic hardening of steel 20Cr2Ni4A. The optimal electrolyte composition for electrolytic-plasma hardening of steels containing $20 \%$ sodium carbonate and $20 \%$ urea has been determined. As a result, a modified layer was obtained on the surface of steel with increased hardness and wear resistance. In this case, the basis of the material does not change, it consists of a ferritic-pearlitic structure, i.e. the part retains its viscous core, and the surface layer contains carbide particles. The presence of carbide particles in the surface layers has a positive effect on the performance properties of the parts, since small carbides keep the products from abrasion.
\end{abstract}

Keywords: Electrolytic plasma, surface hardening, steel, microstructure, wear resistance

\section{INTRODUCTION}

One of the effective methods of surface hardening is electrolytic-plasma treatment, which has recently been very actively introduced into the industry. The main advantages of this method of processing are: high efficiency reaching $85 \%[1,2]$, a considerable depth of hardening from a few micrometers to ten millimeters, possible implementation on simple equipment. It presents an attractive and flexible process for technical applications due to the lack of size limitations and geometric shape, shorter processing time, less environmental impact and lower temperature compared to conventional plasma processes [3-6]. It is possible to produce hardening, chemicalthermal and thermal-cyclic processing of materials which depending on the heating mode, electrolyte composition, design parameters of the equipment. The last decade is actively studying the effect of electrolyteplasma nitriding, cementation and carbonitriding on the structure and properties of steels [7-11]. Nevertheless, many physical processes are still not well understood, for example, phase transformation processes during electrolytic-plzmennoy surface hardening and their influence on tribomechanical properties. The use of plasma electrolytic hardening (PEH) technology for surface hardening provides high-strength modified layers due to the high cooling rate and the absence of decarburization and oxidation processes. This is ensured by the fact that the treatment process is carried out in an electrolyte based on a carbon-containing aqueous solution [12-14]. Present work is devoted to the study of the effect of the PEH process on the structure and properties of steel 20Cr2Ni4A, which is used to make gears, wheels and their rims, as well as other heavy duty parts [15]. Steel $20 \mathrm{Cr} 2 \mathrm{Ni} 4 \mathrm{~A}$ are practically not hardened in the traditional way. Such steels are cemented or carbonitrided and then only heat treated. PEH allows obtain hardened surface layers on the surface of such low-carbon steels, without additional heat treatment. The use of rapid heating, which helps to obtain a finer structure of hardened steel, makes it possible to obtain a more favorable combination of strength and toughness properties. The heating rate has a significant effect on the size of the recrystallized grain, since its increase the number of recrystallization centers grows faster than the growth rate of the centers. This leads to the grinding of grain. Short-term stay of steel in the area of quenching temperatures and phase transitions at temperatures exceeding the equilibrium, lead to mechanical properties that differ from the properties of steel, hardened with heating from traditional heat 
sources [16]. In this regard, the study of the features of changes in the structure and tribomechanical properties of steel 20Cr2Ni4A after PEH is of great scientific and practical interest.

\section{MATERIAL AND RESEARCH METOD}

As the object of study structural alloy steel 20Cr2Ni4A (PN-72 / H-84035) was selected. The choice of material is due to the fact that this steel is widely used in mechanical engineering for the manufacture of gears, wheels and their rims. Samples for the study were cut in the form of parallelepipeds with dimensions of $15 \times 15 \times 10 \mathrm{~mm}$ from a rod, heat-treated in the factory (GOST 4543-71). Table 1 presents the chemical composition of the investigated steel.

Table 1 Chemical composition of steel 20Cr2Ni4A (GOST 4543-71)

\begin{tabular}{c|c|c|c|c|c|c|c|c} 
Steel name & $\mathrm{C}$ & $\mathrm{Si}$ & $\mathrm{Mn}$ & $\mathrm{Ni}$ & $\mathrm{S}$ & $\mathrm{P}$ & $\mathrm{Cr}$ & $\mathrm{Cu}$ \\
\hline 20Cr2Ni4A & $0.16-0.22$ & $0.17-$ & $0.3-0.6$ & $3.25-$ & Up to & Up to & $1.25-$ & Max. 0.3 \\
& & 0.37 & & 3.65 & 0.025 & 0.025 & 1.65 &
\end{tabular}

PEH of steel samples was performed on the unit IEPPM-M (installation for electrolytic-plasma processing of materials - modernized), which was designed and manufactured by the authors at the Research Center "Surface Engineering and Tribology" of S. Amanzholova EKSU [9-11]. The PEH process was carried out in an electrolyte from an aqueous solution containing $20 \%$ sodium carbonate and $20 \%$ urea in the following mode: the applied voltage between the anode and the sample - $320 \mathrm{~V}$, the current density - $25 \mathrm{~A} / \mathrm{cm}^{2}$, and the plasma exposure time - $2 \mathrm{~s}$. In this mode, the samples were heated to $\sim 850-900{ }^{\circ} \mathrm{C}$. Cooling was carried out in a flow-through electrolyte when the voltage was turned off. A general and schematic view of the installation is shown in Figure 1.
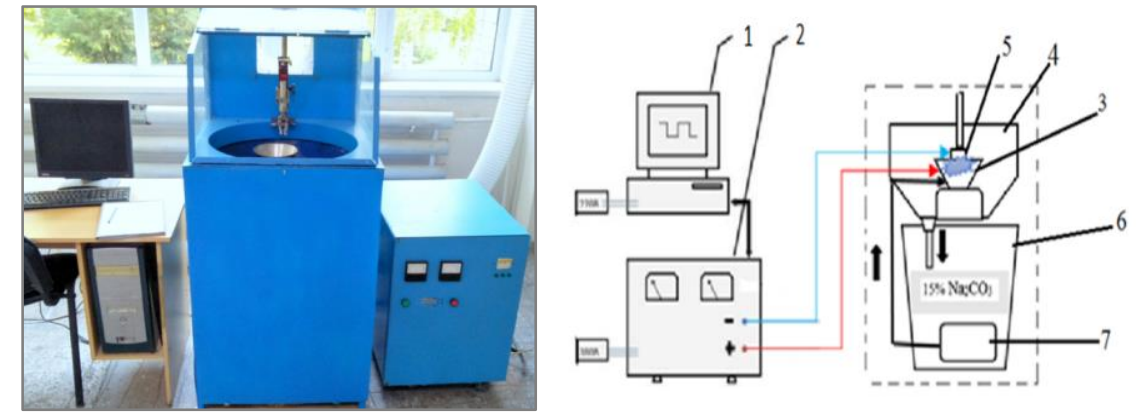

Figure 1 - General and schematic view of the installation IEPPM-M. 1 - personal computer; 2 - power supply; 3 - nozzle for electrolytic-plasma processing (plasma torch); 4 - working bath; 5 - the mechanism for clamping and installing the part or sample; 6 - electrolyte tank; 7 - pump

The surface morphology of samples treated with PEH was studied using an "ALTAMI-MET-1M" optical microscope. To identify the microstructure, chemical etching of thin sections in a $4 \%$ alcohol solution of nitric acid was used (etching time 10-15 s). The microstructure and elemental composition of the sample were examined on a JSM-6390LV scanning electron microscope (SEM), in addition with INCAEnergy energy dispersive microanalysis (EDM).

The research of phase composition of the samples was carried out by X-ray diffraction analysis on an X'PertPro diffractometer using CuKa radiation. The microhardness of the samples was measured by the method of indentation of the diamond indenter on the device PMT-3M in accordance with GOST 9450-76, with a load of $100 \mathrm{~g}$ and an exposure under load of 10s. Tribological tests on sliding friction were carried out on a hightemperature THT-S-BE-0000 tribometer at the Tomsk Materials Sharing Center of Tomsk State University using the standard "ball-disc" method (ASTM G 133-95 and ASTM G 99) [4]. The test scheme is shown in Figure 2. 


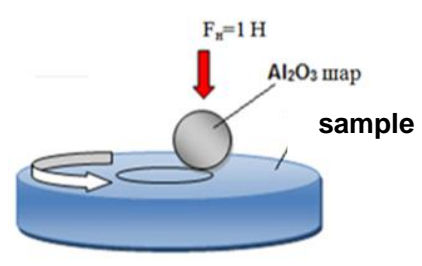

Figure 2 - Tribological testing of samples according to the "ball-disk" scheme

As a counterbody a ball with a diameter of $6 \mathrm{~mm}$ from certified material $-\mathrm{Al}_{2} \mathrm{O}_{3}$ was used. The tests were carried out with a load of $1 \mathrm{H}$ and a linear velocity of $2 \mathrm{~cm} / \mathrm{s}$, a radius of curvature of wear of $5 \mathrm{~mm}$, the friction path was $31.4 \mathrm{~m}$. The tribological characteristics of the modified layer were characterized by wear rate and coefficient of friction. The wear tracks were studied using the contactless 3D profilometer of MICROMEASURE 3D station.

\section{RESULTS AND DISCUSSION}

Figure 3 shows the microstructure of steel 20Cr2Ni4A before and after EPU. Metallographic analysis showed that steel 20Cr2Ni4A in the initial state consists of a ferritic-pearlitic structure. Perlite makes up $\sim 10 \%$ of the total volume. The average grain size of ferrite is $\sim 97 \mu \mathrm{m}$. Martensitic structure is formed after the PEH.
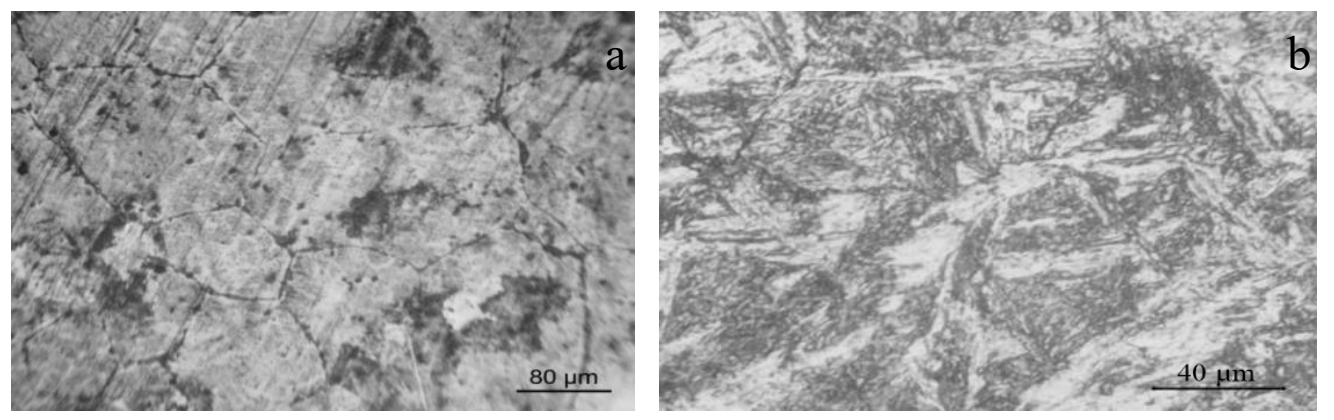

Figure 3 Microstructure of steel surface 20Cr2Ni4A before (a) and after EPU (b)
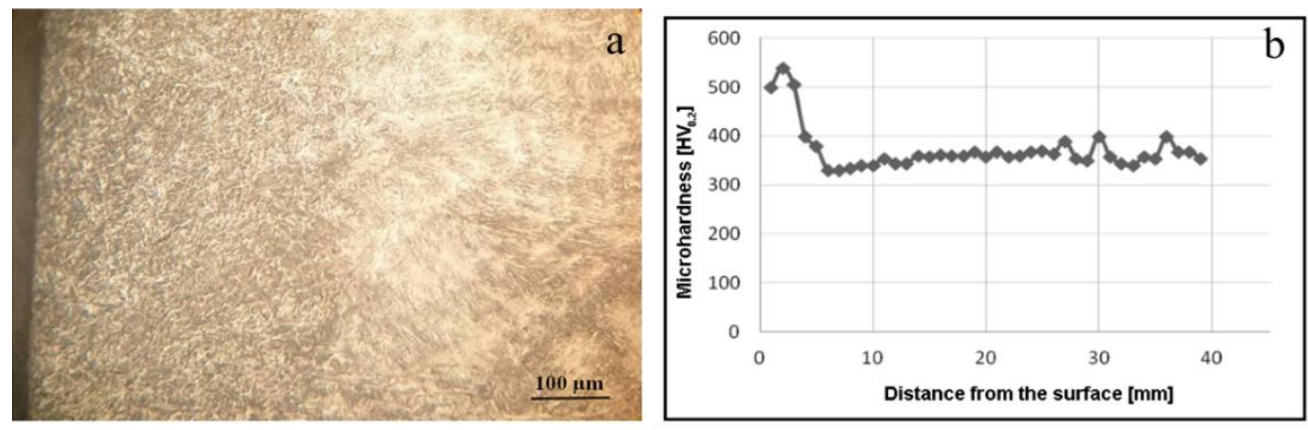

Figure 4 The microstructure of the cross section (a) and the microhardness distribution over the depth (b) of steel 20Cr2Ni4A after PEH

Figure 4a shows an optical micrograph of a cross section of a sample after $\mathrm{PEH}$. It can be seen that the fragment of the near-surface layer has a fine-grained structure, passing to a larger structure of the intermediate layer and further to the base. The thickness of the modified layer is approximately 600-650 microns. The microstructure can be divided into 3 zones: 1 - zone of intense structural transformations, hardened layer; 2 heat affected zone; 3 - zone having the structure of the original matrix. Figure $4 \mathbf{b}$ shows a graph of the change in microhardness over the depth of a sample treated with PEH. Microhardness data confirmed the formation of a martensitic structure. It can be seen a significant increase in microhardness near the surface. The nature 
of the transition zone has a smooth transition from the hardened layer to the base, while the microhardness of the transition zone is slightly less than the base, and the microhardness of the base does not change. Figure $\mathbf{5}$ shows the results of tribological tests of samples of steel 20Cr2Ni4A according to the "ball-disk" scheme. The wear resistance of the images was characterized by the intensity of wear and the volume of wear of samples of steel 20Cr2Ni4A before and after the PEH. It can be seen from Figure 5a that the treated samples show a low wear rate as compared with the original sample. From Figure $\mathbf{5 b}$ it is clear that the samples show a low amount of wear compared to the original sample, which indicates an increase in wear resistance of steel after PEH.
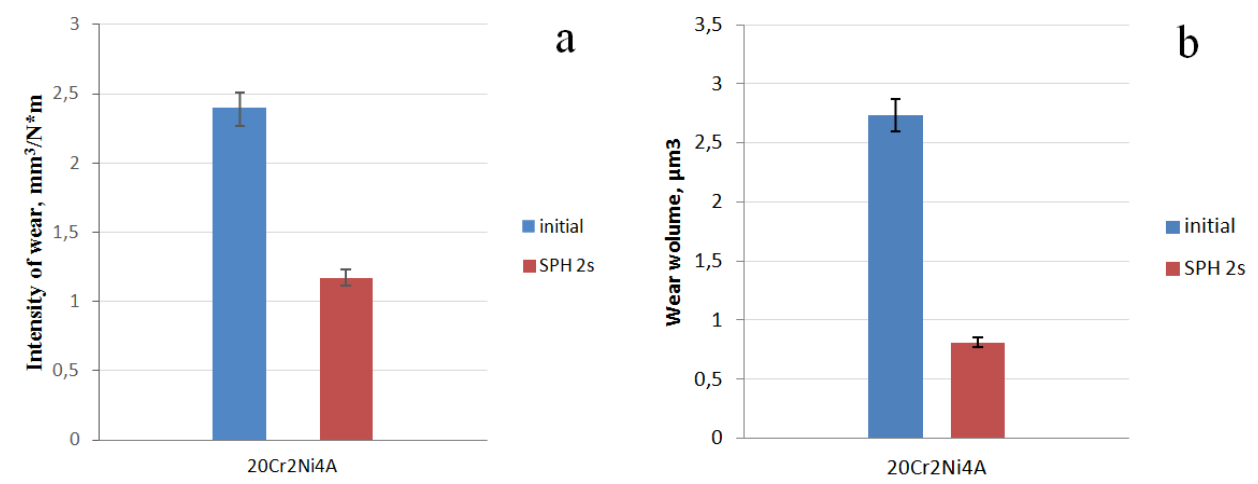

Figure 5 Wear rate and wear volume of steel 20Cr2Ni4A before and after PEH

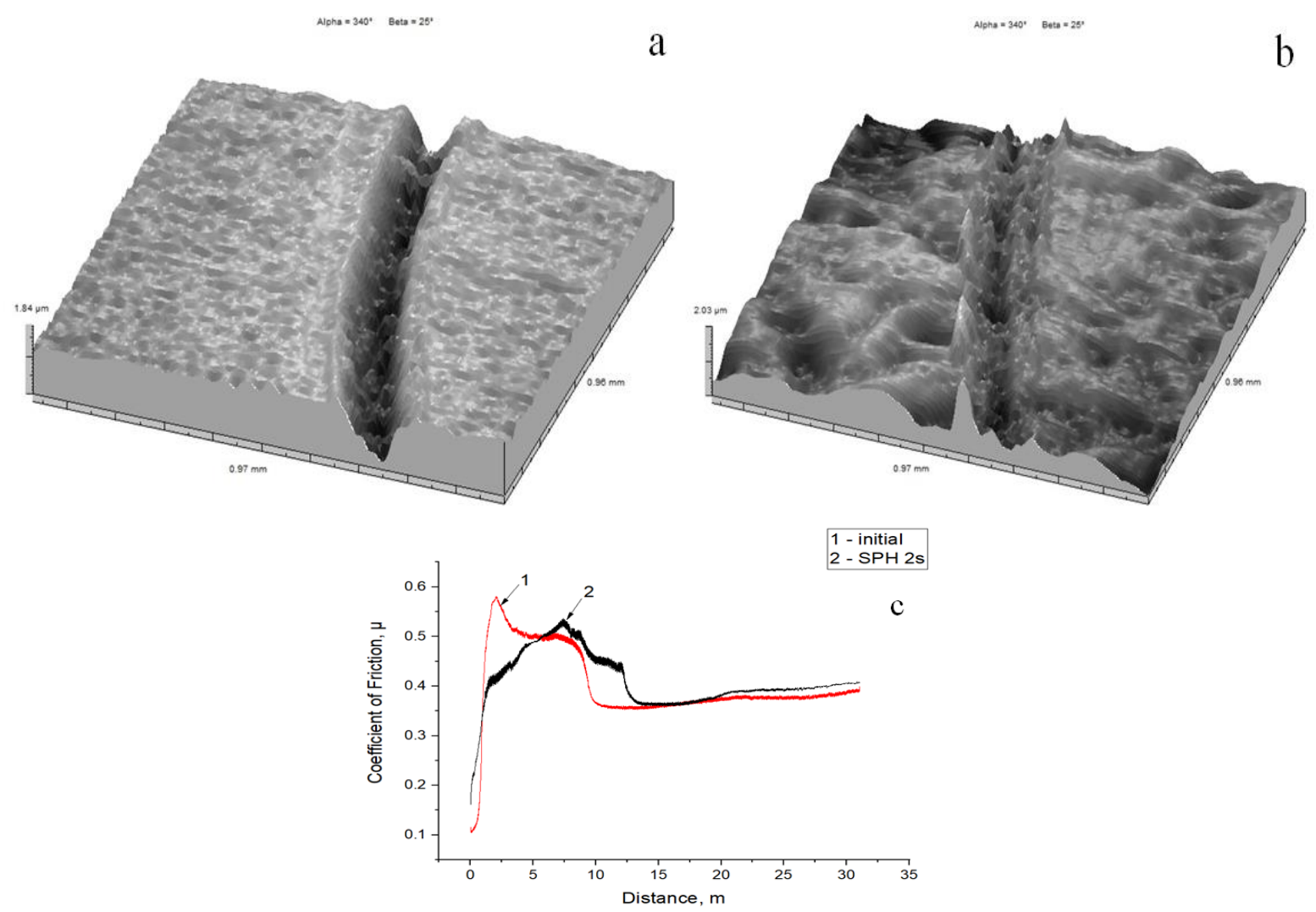

Figure 6 Fragment track image of the initial (a), processed (b) sample and the graph of the change of samples friction coefficient of $20 \mathrm{Cr} 2 \mathrm{Ni} 4 \mathrm{~A}$ steel (c)

We took photos of the tracks of wear of samples of steel 20Cr2Ni4A with the help of a profilometer (Figure 6). It can be said that the depth of the sample track after PEH (Figure 6b) is significantly less compared to the 
untreated sample (Figure 6a) assessing the wear resistance of the samples based on the geometrical parameters of the wear tracks. The shape of the irregularities in general proves once again the improvement in the tribological characteristics of the test sample. Figure $6 \mathrm{c}$ shows a graph of the change in friction coefficient during the test. The measurement results showed slight changes in the friction coefficient.

The phase and elemental composition of the hardened surface layers in comparison with the original sample without treatment were investigated to clarify the structural features that affect the microhardness and wear resistance of steels. Figure 7 shows the X-ray diffraction patterns of steel 20Cr2Ni4A in the initial state (Figure 8a) and after a PEH of 2 seconds duration (Figure 8b). X-ray phase analysis showed that the diffractograms contain $\alpha$-phase lines and weak cementite reflections $\left(\mathrm{Fe}_{3} \mathrm{C}\right)$. The formation of oxide phases after PEH was not detected within the resolution of the X-ray phase analysis method.

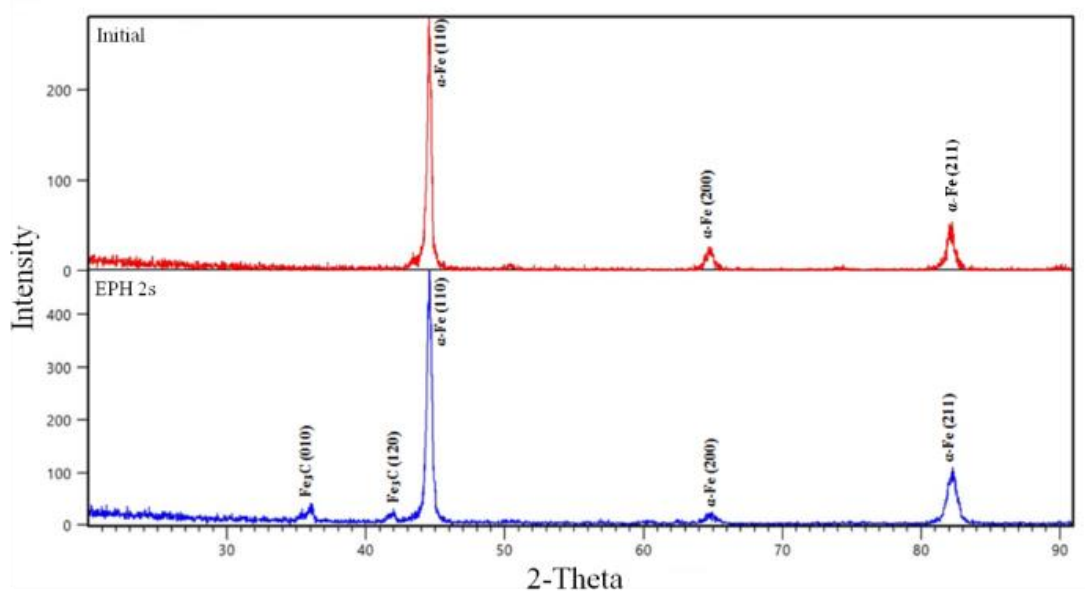

Figure $7 \mathrm{X}$-ray diffraction patterns of 20Cr2Ni4A steel: initial condition and after PEH for $2 \mathrm{~s}$

PEH of the surface of samples of 20Cr2Ni4A steel was carried out before and after PEH with the aim of identifying the changes in the elemental composition of the surface (Figure 8). The analysis showed that after EPU with heating for $2 \mathrm{~s}$, bright crystals (carbide particles) are observed on the surface of steel 20Cr2Ni4A (Figure 8b). However, no significant changes in the elemental composition of the material surface are observed after PEH.
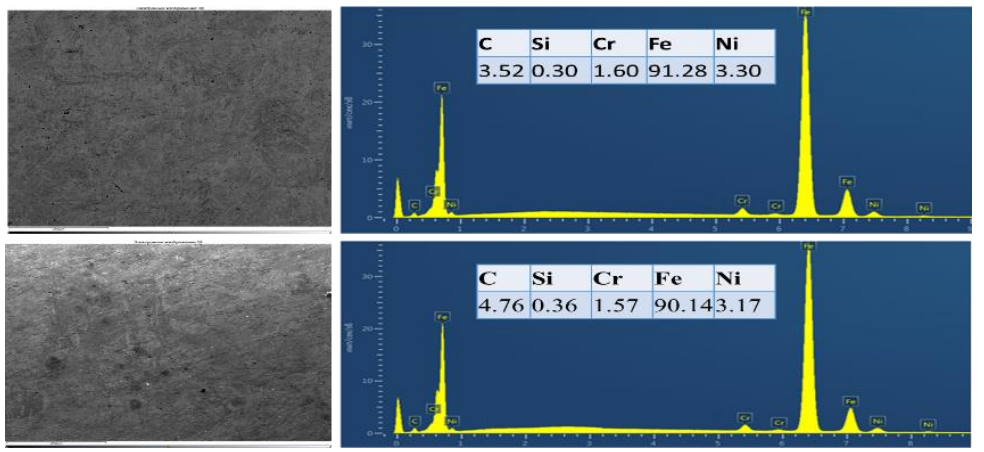

Figure 8 Results of X-ray microanalysis of the surface of steel 20Cr2Ni4A before (a) and after PEH (b)

Thus, conducted research has shown that the EHP method can be used as a method of hardening low carbon 20Cr2Ni4A steel. PEH due to $2 \mathrm{~s}$ in an electrolyte containing $20 \%$ sodium carbonate and $20 \%$ urea, allows you to get hardened surface layers on the surface of low carbon steel without additional heat treatment. PEH ensures the achievement of the technical and economic effect through the use of simple equipment, not expensive aqueous solutions, reducing the processing time, also in the result of increasing the wear resistance and microhardness of $20 \mathrm{Cr} 2 \mathrm{Ni} 4 \mathrm{~A}$ steel. 


\section{CONCLUSION}

1. A modified layer with a thickness of $600-650 \mu \mathrm{m}$ containing cementite $\left(\mathrm{Fe}_{3} \mathrm{C}\right)$ was obtained by methods of $\mathrm{PEH}$ on the surface of steel 20Cr2Ni4A, while the base material does not change and it consists of a ferriticpearlitic structure. The presence of carbide particles in the surface layers has a positive effect on the performance properties of the parts, since small carbides keep the products from abrasion.

2. It is shown that PEH for $2 \mathrm{~s}$ increases microhardness and wear resistance by 2 times. It was found that EPU reduces surface roughness besides of increasing the hardness of the surface layer, which leads to a decrease in friction during operation, and hence an increase in its durability.

\section{ACKNOWLEDGEMENTS}

This paper was performed within the grant financing of scientific research for 2018-2020 of Committee of Science of the Ministry of Education and Science of the Republic of Kazakhstan. Grant BR05236748.

\section{REFERENCES}

[1] KULIKOV, I.S. Electrolyte-plasma processing of materials. Sosny- Minsk: Belaruskaya Navuka, 2010.

[2] BALANOVSKY, A.E. Features of structure formation in medium carbon steels with plasma surface hardening and their effect on the resistance to contact fatigue loads. Moscow: Sciences, 2012.

[3] NISS, V.S., ALEKSEEV, V.G., PARSHUTO, AE, KOROLEV, A.YU. FOMIKHINA, I.V. Investigation of the influence of electrolytic-plasma treatment on the structure and properties of the surface layer of metallic materials. In Surface Engineering. SNPO PM NAS 2011: Materials of Intern. Symposium, New powder composite materials. Welding. Part 2. Minsk: SNPO PM NAS, 2011, pp. 70-73.

[4] ASTM G133 - 95 Standard Test Method for Linearly Reciprocating Ball-on-Flat Sliding Wear.

[5] NEGROV, D. A., BURGONOVA, O. YU., PANTYUKHOVA, K. N., PUTINTSEV ,V. YU. Investigation of the influence of impurities on the structure and reliability of the gear pump. Omsk Scientific Herald. Ser. Aviation rocket and power engineering. 2017, vol. 1, no. 2, pp. 49-56.

[6] TYURIN, Y. N., POGREBNYAK, A. D. Electric Heating Using a Liquid Electrode. Surface and Coatings Technology. 2001, vol. 142-144, pp. 293-299.

[7] SAFONOV, E.N. Plasma hardening of machine parts: monograph. Nizhny Tagil: E.N Safanov, 2014.

[8] YEROKHIN, A.L., NIE, X., LEYLAND, A., MATTHEWS, A., DOWEY, S.J. Plasma electrolysis for surface engineering. Surface and Coatings Technology.1999, vol. 122, pp. 73-93.

[9] RAKHADILOV, B., ZHUREROVA, L., SAGDOLDINA, Z.H. Applying Surface Plasma Hardening for Improving the Tribological Characteristics of Steel Parts. Tribologia, 2019, no. 1, pp. 49-55.

[10] SKAKOV, M., RAKHADILOV, B., SCHEFFLER, M., BATYRBEKOV, E. Microstructure and tribological properties of electrolytic plasma nitrided high-speed steel. Materials Testing. 2015, pp. 360-364.

[11] SKAKOV, M., RAKHADILOV, B., SHEFFLER, M. Influence of electrolyte plasma treatment on structure, phase composition and microhardness of steel P6M5. Key Engineering Materials. 2013, vol. 531-532, pp. 627-631.

[12] SUMIMOV, I.V., BELKIN ,P.N., EPELFELD, A.V. Plasma Electrolytic Modification of the Surface of Metals and Alloys. Tekhnosfera, 2011, vol. 1, pp. 464-468.

[13] FILATOV, YU.A. The structure and conditions of formation of intermediate structures of granular morphology in low carbon low alloy steels of the bainite class. Barnaul: Barnaul Press, 2008.

[14] GOST 23.208-79. Ensuring the durability of products. Method of testing materials for wear resistance under friction on loosely fixed abrasive particles.

[15] SVISHCHENKO, V.V., CHEPRASOV, D.P., IVANAYSKY, A.A. Formation in the intermediate area of structures of granular morphology and some questions of terminology. Polzunovsky almanach. 2003, no. 4, pp. 111-114.

[16] Plasma surface hardening. http://www.awi.su/articles/plazmennaya-poverhnostnaya-zakalka.html. 